\title{
Panduan teknis pelaksanaan pemetaan desa partisipatif
}

Manuel Boissière

Amy E. Duchelle
Stibniati Atmadja

Gabriela Simonet
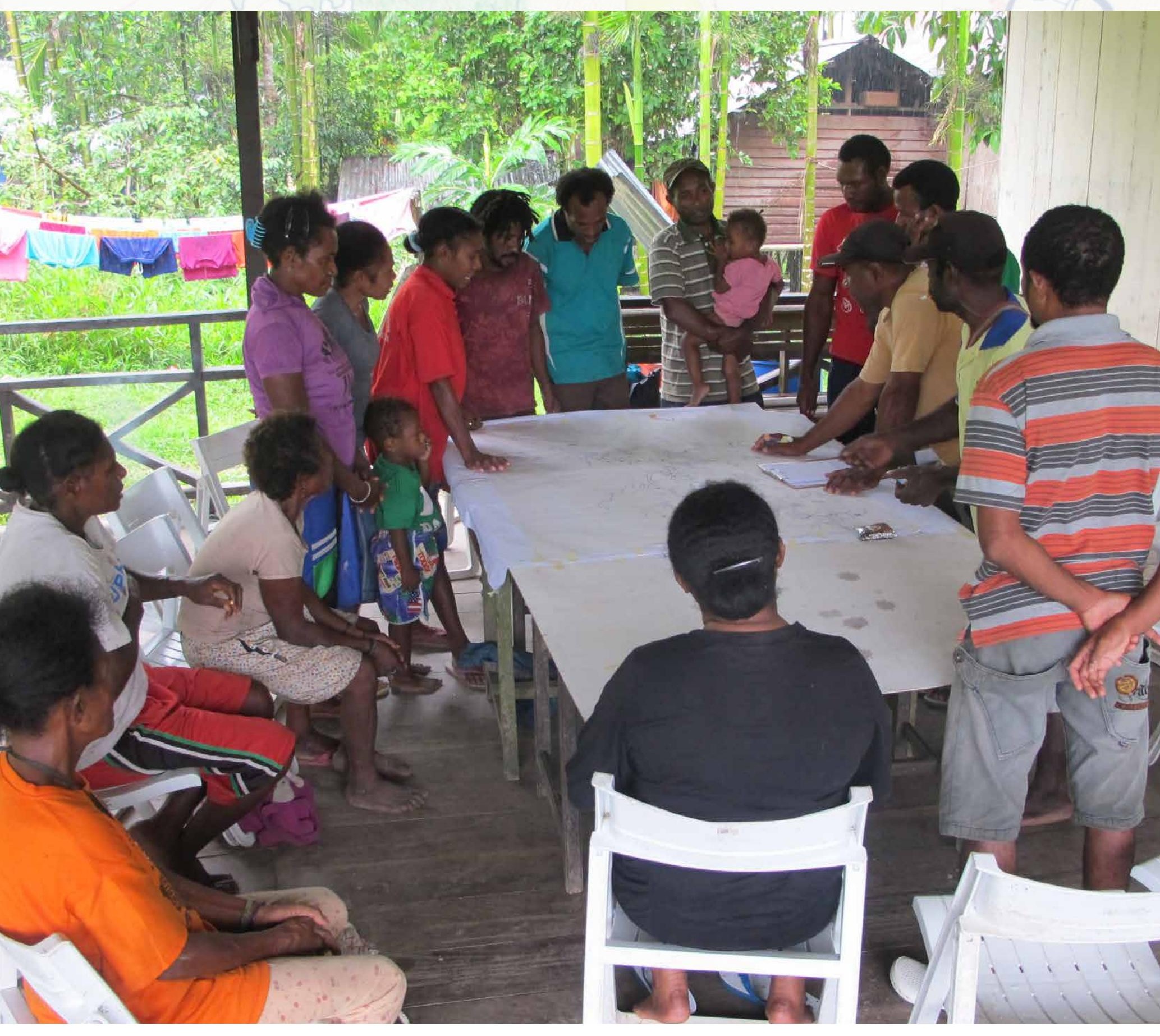



\section{Panduan teknis pelaksanaan pemetaan desa partisipatif}

Manuel Boissière

Pusat Penelitian Kehutanan Internasional (CIFOR) dan Pusat Penelitian Pertanian untuk

Pembangunan Internasional Prancis (CIRAD)

Amy E. Duchelle

CIFOR

Stibniati Atmadja

CIFOR

Gabriela Simonet

Institut Penelitian Pertanian Nasional Prancis (INRA) dan CIFOR 
(c) 2019 Pusat Penelitian Kehutanan Internasional (CIFOR)

DOI: $10.17528 /$ cifor/007338

(c) (i) Materi dalam publikasi ini berlisensi di dalam Creative Commons Attribution 4.0 International (CC BY 4.0), http://creativecommons.org/licenses/by/4.0//

Boissière M, Duchelle AE, Atmadja S dan Simonet G. 2019. Panduan teknis pelaksanaan pemetaan desa partisipatif. Bogor, Indonesia: CIFOR. 19 pp.

Diterjemahkan dari: Boissière M, Duchelle AE, Atmadja S dan Simonet G. 2018. Technical guidelines for participatory village mapping exercise. Bogor, Indonesia: CIFOR. 19 pp.

Foto sampul oleh Manuel Boissière

Pemetaan partisipatif di Mamberamo (Papua/Indonesia)

\author{
CIFOR \\ Jl. CIFOR, Situ Gede \\ Bogor Barat 16115 \\ Indonesia \\ $\mathrm{T}+62(251) 8622-622$ \\ $F+62$ (251) 8622-100 \\ E cifor@cgiar.org
}

\title{
cifor.org
}

Kami ingin berterima kasih kepada para pemangku dana yang telah mendukung penelitian ini melalui kontribusinya terhadap Dana CGIAR. Daftar pemangku dana dapat dilihat dalam: http://www.cgiar.org/about-us/our-funders/

Pandangan yang diungkapkan dalam publikasi ini berasal dari penulis dan bukan merupakan pandangan CIFOR, para penyunting, lembaga asal penulis atau pemangku dana maupun para peninjau buku. 


\section{Daftar isi}

Ucapan Terima Kasih $\quad$ v

1 Pendahuluan 1

2 Peta 2

2.1 Peta dasar 2

2.2 Peta dari citra satelit 2

2.3 Peta pada kertas kalkir 3

3 Daftar material 4

4 Kegiatan pemetaan dengan informan kunci dalam kelompok diskusi kecil 5

4.1 Mempersiapkan salinan peta dasar pada kertas kalkir sebelum memulai kegiatan: 5

4.2 Menambahkan informasi dasar pada salinan peta dasar di kertas kalkir: $\quad 6$

4.3 Memberikan pengantar mengenai kegiatan pemetaan pada informan kunci: $\quad 6$

4.4 Mengakrabkan informan kunci dengan peta: 6

4.5 Minta informan kunci untuk menyempurnakan peta: 6

4.6 Minta informan kunci menjawab pertanyaan survei Desa: 7

$\begin{array}{lll}4.7 & \text { Finalisasi peta: } & 7\end{array}$

5 Kegiatan pemetaan pada pertemuan desa dan perempuan 9

5.1 Sebelum memulai pertemuan dengan peserta: 9

5.2 Persiapan kegiatan: 9

5.3 Mengakrabkan peserta pertemuan desa dan pertemuan wanita dengan

5.4 Minta responden menjawab pertanyaan survei: 11

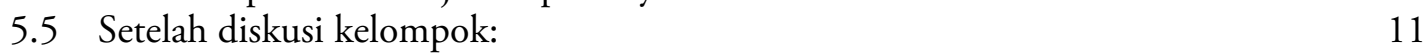

6 Finalisasi peta setelah kerja lapangan $\quad 12$

$\begin{array}{ll}\text { Referensi } & 13\end{array}$ 


\section{Daftar gambar}

1. Mempersiapkan salinan peta dasar pada kertas kalkir.

2. Gambarkan fitur bentang alam dengan penduduk desa pada salinan peta dasar menggunakan kertas kalkir.

3. Peta kepemilikan lahan pada kertas kalkir.

4. Contoh legenda gambar.

5. Proses pemetaan partisipatif. 10

6. Peta bersih. 10

7. Meringkaskan langkah-langkah kegiatan pemetaan partisipatif di desa. 


\section{Ucapan Terima Kasih}

Kegiatan ini merupakan bagian dari Studi Komparatif Global (GCS) mengenai REDD+ CIFOR (CIFOR 2017). Pemangku dana yang mendukung penelitian ini adalah Badan Kerjasama Pembangunan Norwegia (Norad), Departemen Luar Negeri dan Perdagangan Australia (DFAT), Komisi Eropa (EC), Inisiatif Iklim Internasional (IKI) Kementerian Lingkungan Hidup, Konservasi Alam, Bangunan dan Keamanan Nuklir Pemerintah Federal Jerman (BMUB), Departemen Pembangunan Internasional Inggris (UKAID), dan Program Penelitian CGIAR mengenai Hutan, Pohon dan Wanatani (CRP-FTA), serta dukungan pendanaan dari donor yang berkontribusi pada Dana CGIAR. Penulis mengucapkan terima kasih pada semua pihak yang telah memberikan masukan dan komentar selama penyusunan dokumen, serta tim lapangan GCS REDD+ yang telah menerapkan metode ini di lapangan. 



\section{Pendahuluan}

Pelaksanaan pemetaan partisipatif ini dipersiapkan untuk tahap ketiga Studi Komparatif Global (GCS) tentang REDD+ CIFOR. Pemetaan ini merupakan bagian dari komponen penelitian yang telah mengevaluasi dampak intervensi REDD + terhadap hutan dan masyarakat di tingkat tapak sejak 2010, melalui pendekatan KontrolIntervensi Sebelum-Sesudah ("Before-After Control-Intervention"/BACI). Rincian metode komponen penelitian ini terdapat dalam sebuah publikasi CIFOR (Sunderlin et al. 2016). Panduan pemetaan partisipatif ini dikembangkan karena dibutuhkannya sebuah cara yang lebih sistematis dalam mendokumentasikan pemanfaatan lahan dan pengaturan kepemilikan lahan pada beragam lokasi penelitian lapangan kami.

Dokumen ini merujuk kepada kegiatan penelitian lapangan GCS REDD+ ini, meskipun panduan ini dimaksudkan untuk para peneliti, pengawas penelitian lapangan dan enumerator secara umum, yang belum pernah menyusun peta dengan mengikutsertakan masyarakat lokal. Panduan berdasarkan pada beberapa dokumen dan proyek yang dipimpin CIFOR yang menggunakan pemetaan partisipatif sebagai alat untuk mempelajari persepsi lokal terhadap bentang alam dan sudut pandang masyarakat lokal terhadap manajemen hutan dan lahan (van Heist 2000; Sheil et al. 2002; Anau et al. 2003; Boissière et al. 2007; Padmanaba et al. 2012; Kingsolver et al. 2017).

Dalam konteks penelitian lapangan GCS REDD+, pemetaan partisipatif ini merupakan cara untuk mengumpulkan data tentang pertanyaanpertanyaan terkait pemanfaatan dan kepemilikan lahan dalam kuesioner desa dan kuesioner perempuan, serta melakukan pemeriksaan silang data batas desa yang telah dikumpulkan dalam tahap penelitian sebelumnya. Dalam konteks lain, peta seperti ini dapat digunakan sebagai dasar bagi diskusi pemanfaatan lahan (Padmanaba et al. 2012), atau untuk memutuskan bersama dengan masyarakat lokal lokasi di mana survei lapangan mendalam sebaiknya dilakukan (Boissière et al. 2010).

Pemetaan partisipatif ini merupakan bagian dari tiga kegiatan GCS REDD+ di setiap desa penelitian: (1) satu kelompok diskusi kecil dengan sedikitnya tiga informan kunci untuk mengetahui batas desa, kepemilikan lahan, kawasan sengketa, akses (jalan) dan lokasi pasar; (2) pertemuan desa dengan 10-15 lelaki dan perempuan dewasa; dan (3) pertemuan perempuan dengan 10-15 perempuan dewasa. Pemetaan dilakukan dengan kelompok diskusi kecil. Hasil pemetaan awal tersebut digunakan untuk pertemuan desa dan pertemuan perempuan. 


\section{Peta}

Kegiatan pemetaan memerlukan peta dasar yang perlu dipersiapkan terlebih dahulu oleh ahli Sistem Informasi Geografis (GIS). Lokasi dan batas desa (dalam bentuk Shapefiles) telah diperoleh pada tahap penelitian sebelumnya menggunakan sumber data sekunder atau melalui pemetaan dengan penduduk desa, jika informasi spasial batas desa tidak tersedia (lihat Sunderlin et al. 2016, 66-67).

Tiga buah peta diperlukan dalam kegiatan pemetaan: peta dasar, peta/citra satelit dan salinan peta dasar di atas kertas kalkir.

\subsection{Peta dasar}

Peta dasar adalah peta kasar, dengan jumlah fitur minimal yang diperlukan untuk membantu informan kunci menentukan orientasi di lokasi tertentu. Ahli GIS mengekstraksi fitur-fitur tersebut dari citra satelit (mis. Landsat, Sentinel atau citra satelit gratis lain yang tersedia untuk lokasi berbeda). Peta dasar dicetak di kertas ukuran A0 (841x1189mm), untuk membantu agar dapat memasukkan tengara ("landmark") penting dan nama sebanyak mungkin. Daftar berikut ini menunjukkan sejumlah tengara dan fitur lain, tidak terlalu lengkap, untuk dimasukkan ke dalam peta dasar:

a. posisi pemukiman (mis. desa utama, dusun, pondok)

b. jalan, jalan setapak, bandara/lapangan udara

c. bangunan keagamaan (mis. gereja, masjid, rumah adat), jika tampak dalam citra satelit (atau jika lokasi dari Global Positioning System/GPS)-nya telah tersedia dari survei lapangan sebelumnya)

d. bangunan lain yang diketahui oleh penduduk desa (mis. kantor pemerintah, bangunan komunal, koperasi, sekolah), jika tampak pada citra satelit (atau jika posisi GPS-nya telah tersedia dari survei lapangan sebelumnya)

e. sungai, kali, kolam, danau f. gunung, bukit (tampak pada peta berbasis citra satelit, namun ditampilkan hanya dengan ikon, misalnya, segitiga dalam peta dasar)

g. koordinat geografis (disarankan menggunakan Universal Transverse Mercator (UTM))

h. batas desa yang telah diidentifikasi pada kunjungan lapangan sebelumnya.

Daftar ini dapat diadaptasi untuk fitur-fitur yang dipandang penting bagi tiap lokasi/negara. Perlu dimasukkan seluruh fitur tersebut dalam peta dasar agar peta mudah dipahami oleh informan kunci dan responden lain, dan mereka tahu di mana menggambar ketika ditanya oleh pengawas/ enumerator penelitian lapangan.

\subsection{Peta dari citra satelit}

Sebuah peta dasar dari citra satelit akan digunakan untuk mendukung diskusi dengan penduduk desa. Peta ini harus menggunakan interpretasi citra satelit sesedikit mungkin, karena jika tidak, akan terlalu 'ribet' dan menyita waktu dalam mempersiapkannya. Peta ini berisi tengara yang sama dengan yang di peta dasar. Koordinat geografis ditampilkan untuk membantu digitalisasi setelah kerja lapangan. Intrepretasi citra satelit yang minimal dilakukan oleh ahli GIS, mencakup wilayah hutan dan non-hutan, permukiman dan badan air. Informasi dari interpretasi satelit hanya bersifat indikatif, dan bukan definitif. Peta ini akan digunakan untuk mengecek jawaban penduduk atas pertanyaan survei (mis. keberadaan hutan terdegradasi, area konversi lahan).

Idealnya, peta dicetak berwarna dengan resolusi tinggi pada kertas ukuran $\mathrm{A} 0$ agar bisa ditumpangsusunkan dengan peta dasar. Citra satelit resolusi tertinggi dan bebas awan yang ada untuk lokasi penelitian sebaiknya digunakan. Citra peta tersebut dicetak menggunakan kertas foto 
atau terlaminasi agar terlindung dari kelembaban. Jika terlalu mahal atau secara teknis sulit mencetak pada A0, maka dapat diganti dengan peta lebih kecil. Kami sangat menyarankan agar tidak lebih kecil dari ukuran A2. Peta cetakan ini dapat dipajang di desa agar penduduk desa terbiasa dengan peta sebelum kegiatan pemetaan, dan kemudian mengidentifikasi kawasan di mana hutan telah dibuka.

\subsection{Peta pada kertas kalkir}

Peta pada kertas kalkir akan digunaan untuk mencatat data dari diskusi kelompok kecil. Peneliti perlu menyalin koordinat geografis dan seluruh tengara penting dari peta dasar ke peta kalkir menggunakan spidol permanen (tahan air). Selama diskusi kelompok kecil dengan informan kunci, peneliti akan melakukan tumpang susun peta pada kertas kalkir di atas peta dasar. Kami sangat menyarankan untuk menggunakan pensil (2B atau warna) selama kegiatan pemetaan dengan informan kunci, mengingat pensil tidak mudah terhapus oleh kelembaban atau hujan, dan dapat dengan mudah diperbaiki, serta cukup terlihat untuk keperluan digitalisasi peta setelah kerja lapangan.

Kertas kalkir biasanya tersedia dalam gulungan 20 atau $50 \mathrm{~m}$ di toko buku. Kertas kalkir perlu dipersiapkan terlebih dahulu, dan dipotong untuk ukuran A0 agar sesuai dengan peta dasar. Dua salinan peta dasar pada kertas kalkir perlu dipersiapkan sebelum ke lapangan. 


\section{Daftar material}

Material atau bahan berikut ini perlu dipersiapkan sebelum ke lapangan. Lebih baik membelinya di kota besar, mengingat sebagian material ini tidak tersedia di kota kecil di pedesaan:

a. 1 set peta (peta dasar, salinan peta dasar dan citra satelit terbaru) untuk tiap desa survei

b. 1 gulung kertas kalkir (sebagai cadangan)

c. spidol permanen beragam warna untuk menggambar fitur-fitur utama pada salinan peta di kertas kalkir

d. pensil (2B atau warna) lengkap dengan banyak penghapus (tempelkan penghapus untuk tiap pensil dengan selotip agar tidak hilang

saat kerja lapangan)

e. minimal 2 pisau kertas (cutters)

f. 1 gunting besar

g. minimal dua penggaris (panjang $30 \mathrm{~cm}$ )

h. 2 gulung selotip (lebar $1 \mathrm{~cm}$ )

i. $\quad 2$ atau 3 tabung plastik untuk melindungi peta dasar, citra satelit dan peta di atas kertas kalkir setelah digambar.

j. 1 kalkulator untuk menghitung lokasi titik GPS pada peta dasar 


\section{Kegiatan pemetaan dengan informan kunci dalam kelompok diskusi kecil}

\subsection{Mempersiapkan salinan peta dasar pada kertas kalkir sebelum memulai kegiatan:}

Waktu yang diperlukan: sekitar $1 / 2$ jam per salinan peta dasar pada kertas kalkir

Peta ini perlu disalin sebelum ke lokasi, meski bisa juga dilakukan sebelum pergi ke lapangan nanti.

Langkah-langkahnya sebagai berikut:

- Tumpang susunkan kertas kalkir pada peta dasar dan gunakan selotip untuk menahan peta dasar dan kertas kalkir di atas meja (Gambar 1).
- Tambahkan tengara atau fitur penting pada kertas kalkir dari peta dasar, yang nanti akan membantu tumpang susun kertas kalkir pada peta dasar saat diskusi kelompok kecil dengan informan kunci. Fitur-fitur ini akan membantu mengarahkan peneliti dan pserta saat menggambar di kertas kalkir pada diskusi kelompok, dan peta ini akan berfungsi sebagai cadangan jika peta dasar hilang atau rusak.

- Seluruh tengara penting (sungai, pemukiman, jalan) harus didokumentasikan menggunakan spidol permanen dengan warna berbeda (mis. hitam untuk jalan dan desa, biru untuk sungai). Batas desa harus ditandai dengan pensil

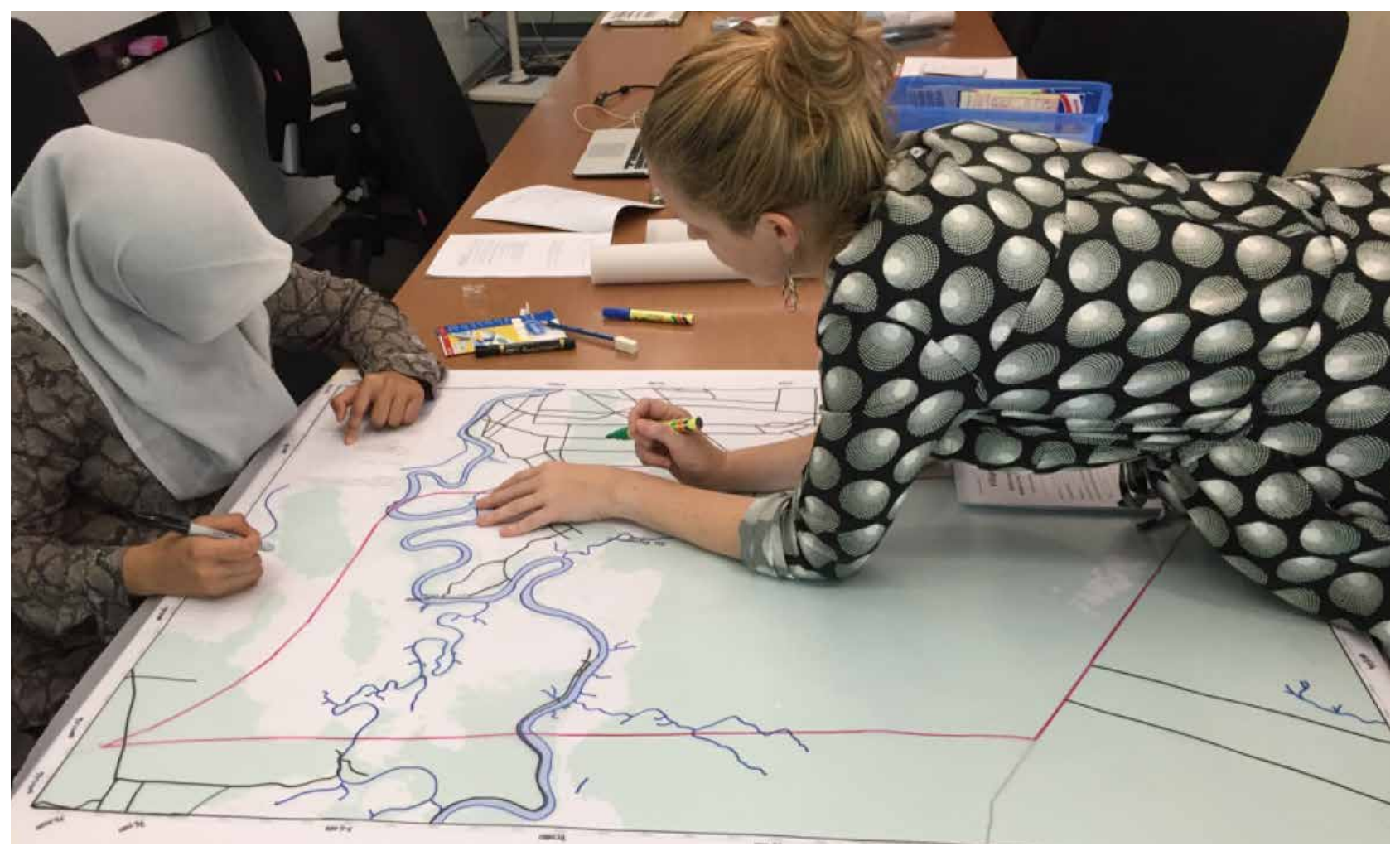

Gambar 1. Mempersiapkan salinan peta dasar pada kertas kalkir.

Catatan: Tambahkan fitur dasar dan tengara, dengan peta dasar sebagai latar belakang (Kredit: Manuel Boissière) 
(2B) karena bisa berubah setelah kegiatan pemetaan pertama pada diskusi grup kecil. Tambahkan nama beragam fitur berbeda jika memungkinkan (nama desa, sungai, dll.).

- Boleh menggambar tanda X pada 4 sudut peta, atau membuat garis kerangka luar peta (untuk nanti mempermudah tumpang susun peta dasar, yang telah memiliki garis kerangka luar), dan tambahkan koordinat geografis UTM yang telah dipersiapkan pada peta dasar oleh spesialis GIS. Koordinat ini akan bermanfaat jika peta tercampur, dan jika sebuah fitur yang memiliki koordinat GPS harus ditambahkan dalam peta (mis. lokasi pasar).

\subsection{Menambahkan informasi dasar pada salinan peta dasar di kertas kalkir:}

Waktu yang diperlukan: sekitar 10 menit per salinan peta dasar pada kertas kalkir.

Gunakan pensil, gambarlah persegi panjang (mis. $10 \times 20 \mathrm{~cm}$ ) pada bagian sisi kertas dan tuliskan informasi berikut:

a. nama desa dan inisiatif REDD+

b. awal dan akhir waktu praktik pemetaan

c. nama pengawas/enumerator penelitan

lapangan yang melakukan pemetaan.

Peta dasar asli disimpan sebagai cadangan jika peta kertas kalkir hilang atau rusak, atau jika peta baru diperlukan. Sebelum berangkat ke lokasi lapangan, siapkan sedikitnya dua salinan peta dasar pada kertas kalkir: salinan pertama untuk kepemilikan lahan dan area sengketa (draft); dan salinan kedua sebagai versi peta final berdasarkan salinan pertama.

\subsection{Memberikan pengantar mengenai kegiatan pemetaan pada informan kunci:}

Paparkan dengan jelas pada informan kunci bahwa peta akan digunakan untuk apa, dan tidak akan digunakan untuk apa. Peta tidak akan digunakan untuk kebutuhan formal seperti demarkasi/ pemetaan lahan, dan tidak akan disebarkan ke luar tim penelitian, misalnya pada pihak swasta, pemerintah daerah atau pelaksana REDD+. Paparkan dengan jelas apa yang akan dilakukan selama diskusi kelompok kecil tersebut, dan apa yang akan dilakukan pada pertemuan lebih besar tingkat desa dan pertemuan perempuan. Jelaskan bahwa penggunaan peta (mis. untuk publikasi ilmiah) akan menjaga anonimitas desa, atau akan meminta persetujuan pihak desa jika perlu mencantumkan nama atau lokasi desa. Namanama informan kunci dalam kegiatan pemetaan akan dicatat untuk keperluan internal tapi tidak dicantumkan dalam publikasi. Beri waktu untuk tanya jawab dan untuk mengatasi kekhawatiran yang ada.

\subsection{Mengakrabkan informan kunci dengan peta:}

Ketika memulai diskusi kelompok kecil, pastikan setiap orang memahami peta dasar; minta mereka menunjukkan pusat desa di peta dan periksa apakah setiap orang mengenali beragam fitur dan tengara.

\subsection{Minta informan kunci untuk menyempurnakan peta:}

Menggunakan selotip, tempelkan peta dasar pada permukaan rata (mis. meja sekolah, lantai datar atau pada meja/lantai dengan papan flipcharts jika meja/lantai tidak rata). Tempatkan kertas kalkir di atas peta dasar dan sejajarkan kertas kalkir dengan peta sesuai fitur-fitur yang sebelumnya ditambahkan pada kertas kalkir. Siapkan peta/citra satelit di tempat yang mudah dijangkau jika sesekali diperlukan selama praktik untuk mendukung atau memeriksa koreksi dari informan kunci. Kegiatan bisa dimulai.

Minta informan kunci untuk mengubah/ menambahkan tengara apapun yang mungkin salah atau belum ada. Mulai dengan batas desa (lihat Bagian 1B.5 Kuesioner desa). Sebagai mana disebutkan sebelumnya, batas tersebut telah diperkirakan dan digeoreferensikan pada survei sebelumnya, namun lebih baik memeriksa kembali dan mengkoreksi jika diperlukan. Minta peserta untuk mengidentifikasi lokasi penting, nama unit bagian desa berbeda atau pemukiman, jalan utama, sungai besar dan badan air lain. Salinan peta dasar pada kertas kalkir akan digunakan di seluruh lanjutan praktik pemetaan dengan menumpangsusunkan pada peta dasar. 


\subsection{Minta informan kunci menjawab pertanyaan survei Desa:}

Tujuannya adalah untuk mengumpulkan data yang menjawab pertanyaan terkait dalam

Kuesioner desa:

- Lokasi jalan terdekat (Bagian 1C.24 dan 1C.25 Kuesioner desa).

- Lokasi pasar terdekat (Bagian 1C.28 Kuesioner desa). Jika pasar berada di luar zona tutupan peta dan terlalu jauh untuk dijangkau selama survei, maka paparan singkat mengenai lokasi pasar (termasuk nama lokasi; lihat Bagian 1C.28a Kuesioner desa) akan ditambahkan pada lembar kuesioner. Posisi GPS pasar harus diambil jika memungkinkan.

- Identifikasi de jure dan de facto kategori kepemilikan lahan yang diterapkan pada tiap bagian wilayah desa.

- Identifikasi kawasan dengan akses terbatas vs terbuka (Tabel 5 Kuesioner desa).

- Identifikasi kawasan lahan sengketa (Bagian 5 Kuesioner desa).

Jelaskan kembali apa yang akan ditanyakan pada responden. Gunakan pensil 2B untuk menggambar pada peta, dengan kode (warna, simbol atau bentuk yang disepakati) untuk kategori kepemilikan lahan berbeda. Kode perlu disepakati sebelum kegiatan dimulai. Beri tanda pada peta di mana lokasi pasar terdekat, jika ada dalam peta. Pastikan seluruh informan kunci menyepakati jawaban sebelum menambahkan apapun pada peta. Lebih baik jika ada salah seorang informan kunci dapat menggambarkan fitur, kategori kepemilikan lahan, dll. pada kertas kalkir. Namun jika tidak ada relawan, maka pengawas penelitian lapangan atau enumerator dapat menggambarkannya (Gambar 2).

\subsection{Finalisasi peta:}

Pastikan tidak ada yang ingin menambahkan apapun pada peta atau mengkoreksi apa yang telah digambar (Gambar 3). Tuliskan pada peta, dengan spidol, nama informan kunci, waktu, nama desa dan nama kegiatan (merujuk ke Kuesioner desa). Tambahkan pula legenda, dengan seluruh kode warna/bentuk yang digunakan selama praktik pemetaan harus jelas diidentifikasi (lihat contoh legenda pada Gambar 4). Ambil foto peta (Gambar 3). Informasi kepemilikan lahan dan area sengketa akan dibuat di atas salinan peta dasar di kertas kalkir yang sama.

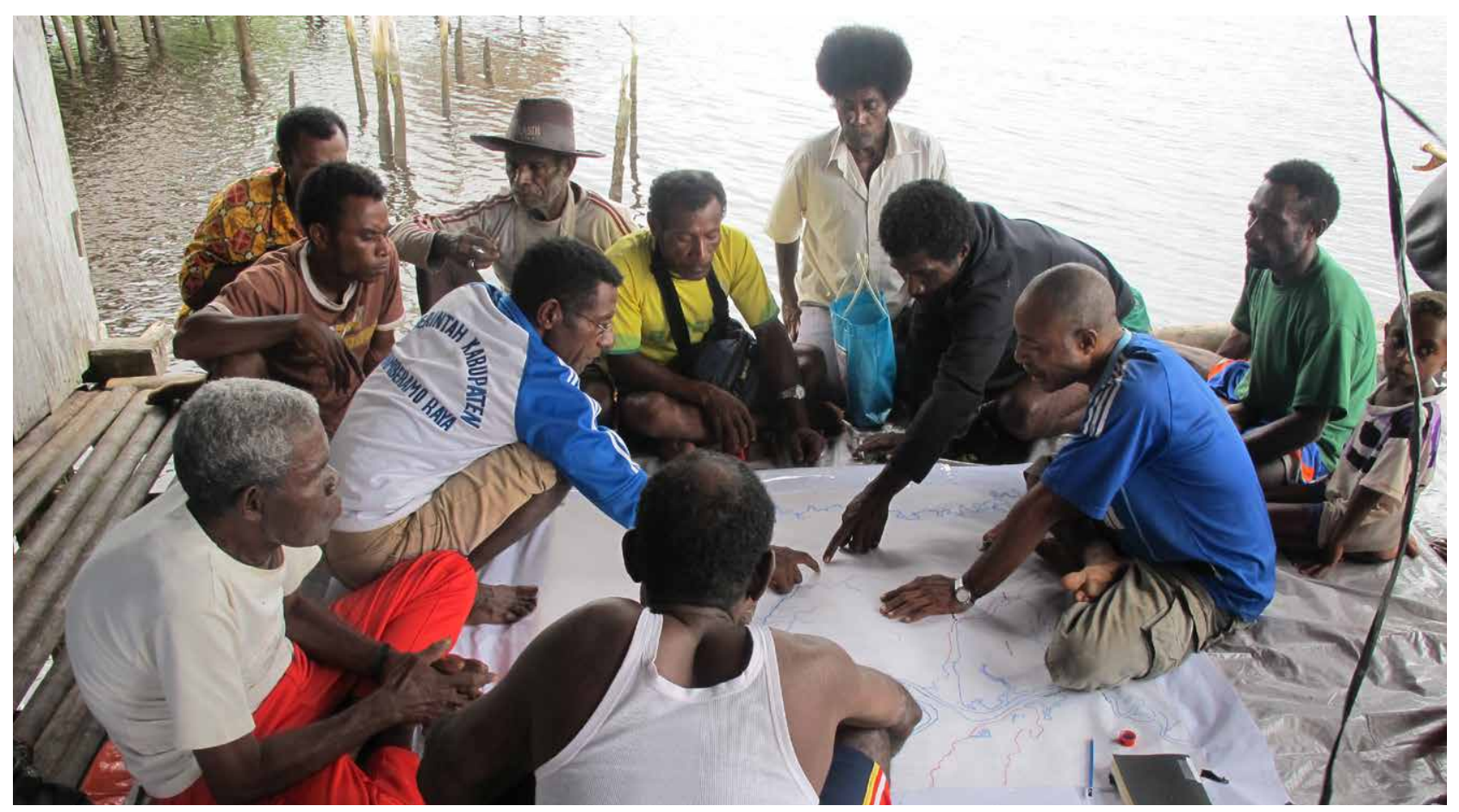

Gambar 2. Gambarkan fitur bentang alam dengan penduduk desa pada salinan peta dasar menggunakan kertas kalkir.

Kredit: Manuel Boissière 


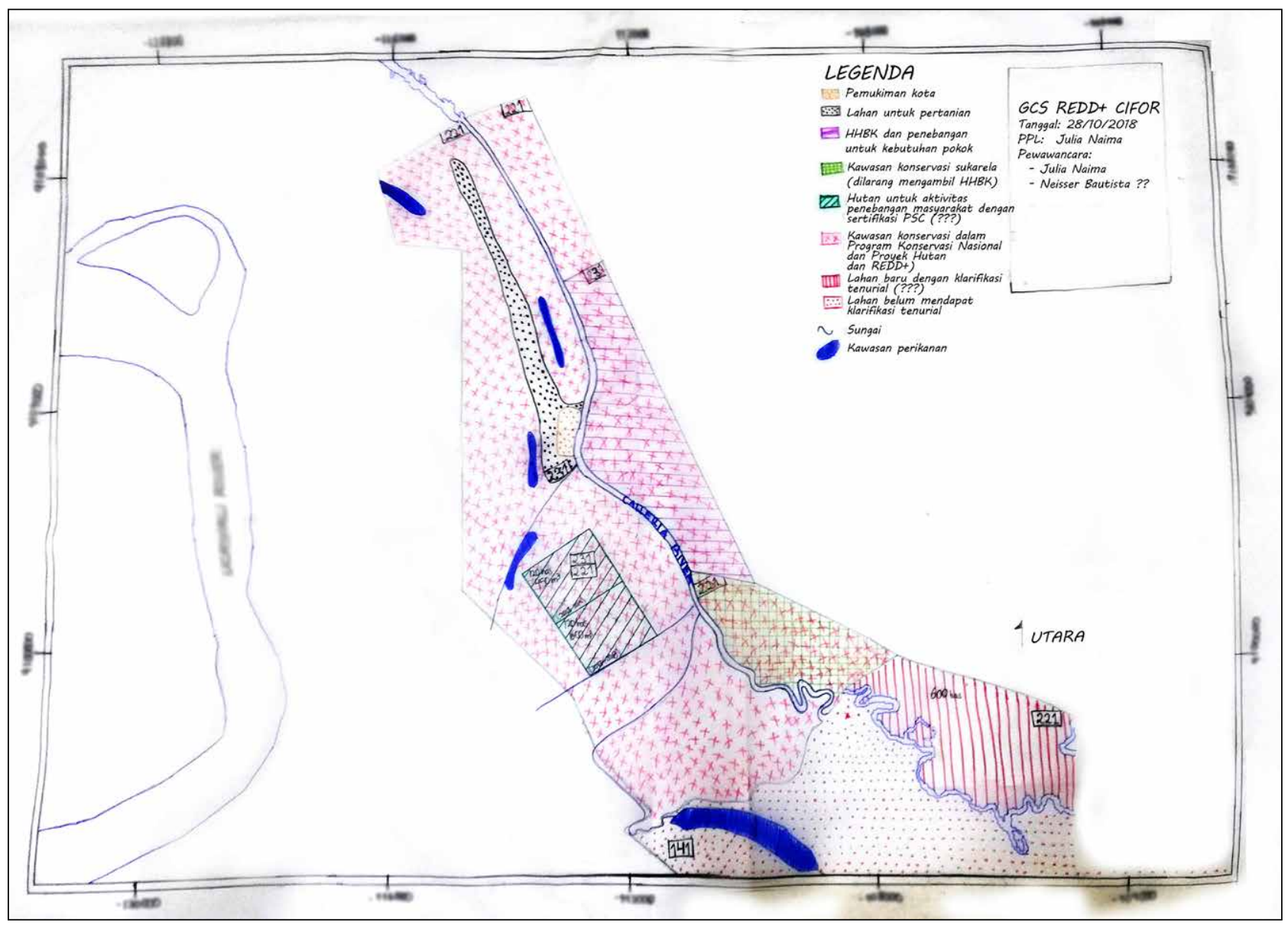

Gambar 3. Peta kepemilikan lahan pada kertas kalkir.

Kredit: Julia del Carmen Naime Sanchez Henkel

Gambar 4. Contoh legenda gambar.

Catatan: Tambahkan secara langsung legenda pada peta bersih, termasuk seluruh fitur dari peta dasar dan semua fitur dari kegiatan pemetaan. Gunakan warna dan bentuk secara konsisten selama kegiatan. Kredit: Vivi Selviana

\begin{tabular}{|l|}
\hline Kabupaten Katingan \\
Provinsi Kalimantan Tengah \\
Proyek Katingan Mentoya \\
26 Agustus 2018 \\
PPL (Pengawas Penelitian Lapangan): \\
Fika Anggraini, Karlina \\
Kegiatan: \\
Pemetaan Partisipatoris Tenurial Lahan \\
LEGENDA \\
$:$ Sungai \\
: Jalan \\
: Batas Desa \\
: Batas Kabupaten \\
: Permukiman \\
: Kebun Masyarakat \\
: Sawah \\
: Lokasi tambang \\
: Bekas lokasi tambang \\
: Semak \\
: Kelapa sawit \\
:Han
\end{tabular}




\section{Kegiatan pemetaan pada pertemuan desa dan perempuan}

Bagi GCS REDD+, tujuan kegiatan pemetaan pada pertemuan desa dan perempuan adalah untuk menggunakan peta yang telah dihasilkan saat diskusi dengan informan kunci untuk mengumpulkan informasi lebih mengenai:

- perubahan tutupan hutan dalam 2 tahun terakhir untuk berbagai jenis kepemilikan lahan

- perubahan kualitas hutan (degradasi/pengayaan dalam 2 tahun terakhir untuk berbagai jenis kepemilikan lahan.

Hal tersebut di atas merujuk pada Tabel 7A dan 7B Kuesioner desa dan Tabel 1C2 dan 1C3 Kuesioner perempuan.

Pertemuan desa dan pertemuan perempuan idealnya dilakukan sehari setelah diskusi dengan kelompok kecil informan kunci, karena akan menggunakan peta hasil diskusi tersebut.

\subsection{Sebelum memulai pertemuan dengan peserta:}

Buat peta salinan/versi bersih dari peta hasil diskusi dengan informan kunci selama diskusi kelompok kecil pada kertas kalkir baru, karena fitur yang digambar selama kegiatan pemetaan pertama mungkin tidak rapi (Gambar 5 dan 6).

Pada salinan bersih, berhati-hatilah menyalin peta sehingga persis sama dengan yang disusun selama diskusi kecil informan kunci. Jangan gunakan spidol permanen dalam mereproduksi informasi yang asalnya digambar menggunakan pensil warna atau hitam. Alasannya, peserta pada pertemuan desa atau pertemuan perempuan mungkin ingin memodifikasi sesuatu di peta bersih. Hal ini tidak mungkin dilakukan jika sudah menggunakan spidol. Alasan lain, adalah untuk membedakan data yang dimasukkan di lapangan (yaitu menggunakan pensil) dari data yang dikembangkan spesialis GIS. Mengingat spesialis GIS lah yang akan mendigitalisasi seluruh peta pasca-kerja lapangan, menjadi penting agar bagian yang digambar penduduk desa dapat dibedakan dari fitur peta dasar, untuk menghindari kesalahan dan kebingungan.

\subsection{Persiapan kegiatan:}

Sebagaimana kegiatan pemetaan dengan informan kunci sebelumnya, paparkan dengan jelas kepada peserta pertemuan desa dan pertemuan perempuan bahwa peta akan digunakan untuk apa, dan peta tidak akan digunakan untuk apa (bukan untuk penggunaan resmi, bukan untuk demarkasi lahan, dan bukan untuk digunakan oleh pihak swasta, pemrakarsa REDD+ dll.). Jelaskan pada peserta bagaimana peta akan digunakan selama pertemuan. Jelaskan bahwa penggunaan peta (mis. untuk publikasi ilmiah) akan menjaga anonimitas desa, atau akan meminta persetujuan pihak desa jika perlu mencantumkan nama atau lokasi desa. Namanama informan kunci dalam kegiatan pemetaan akan dicatat untuk keperluan internal tapi tidak dicantumkan dalam publikasi. Sediakan waktu untuk tanya jawab dan mengatasi kehawatiran. Bahkan jika peserta pertemuan desa dan pertemuan perempuan tidak melakukan koreksi atau pembaruan pada peta dari diskusi informan kunci, informasi ini tetap perlu diberikan.

\subsection{Mengakrabkan peserta pertemuan desa dan pertemuan wanita dengan peta dan meminta penyempurnaan:}

Pendekatan serupa dengan diskusi kelompok kecil informan kunci perlu dilakukan, meski dengan cara yang lebih cepat, terkecuali jika ada 


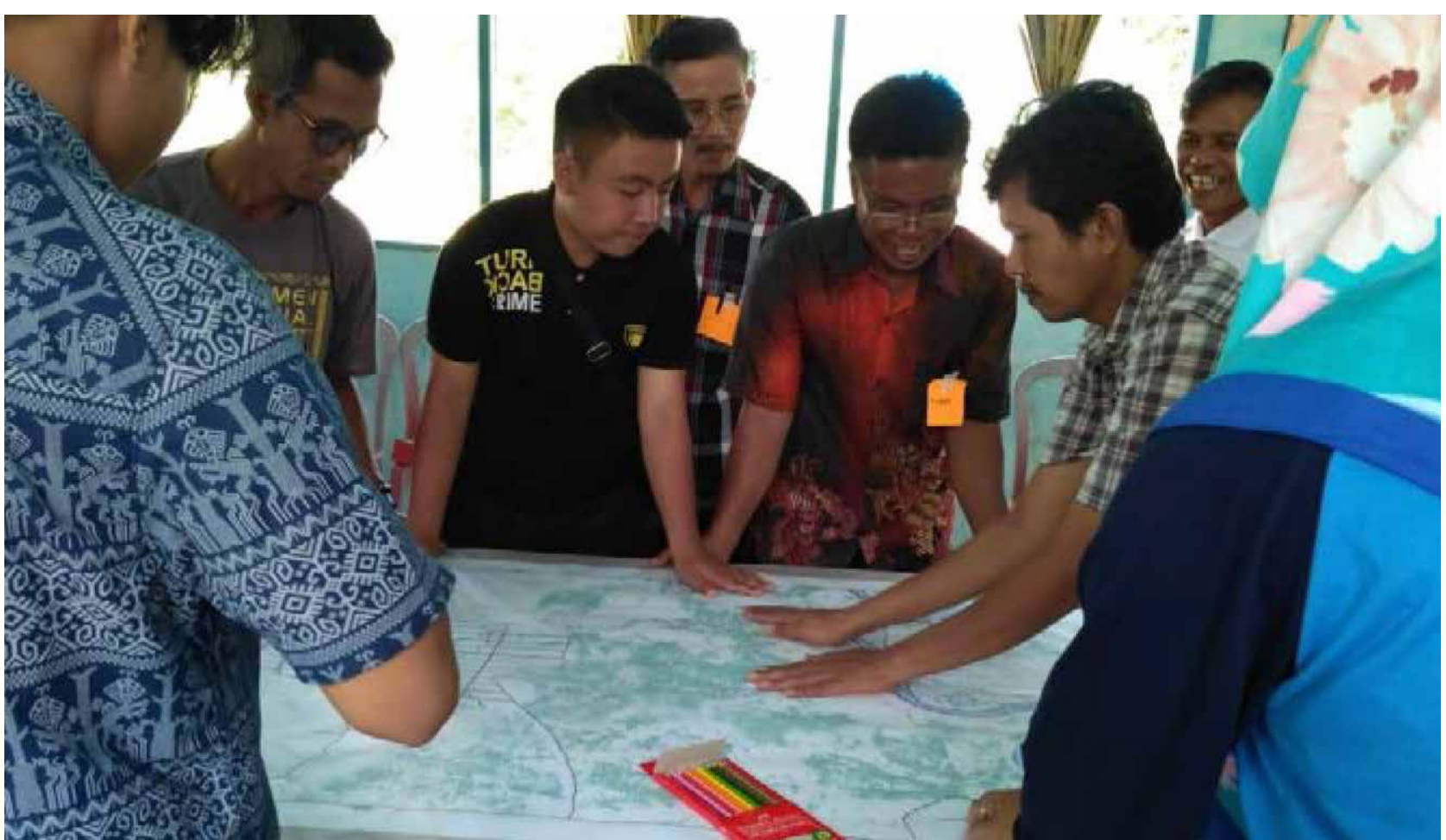

\section{Gambar 5. Proses pemetaan partisipatif.}

Kredit: Vivi Selviana

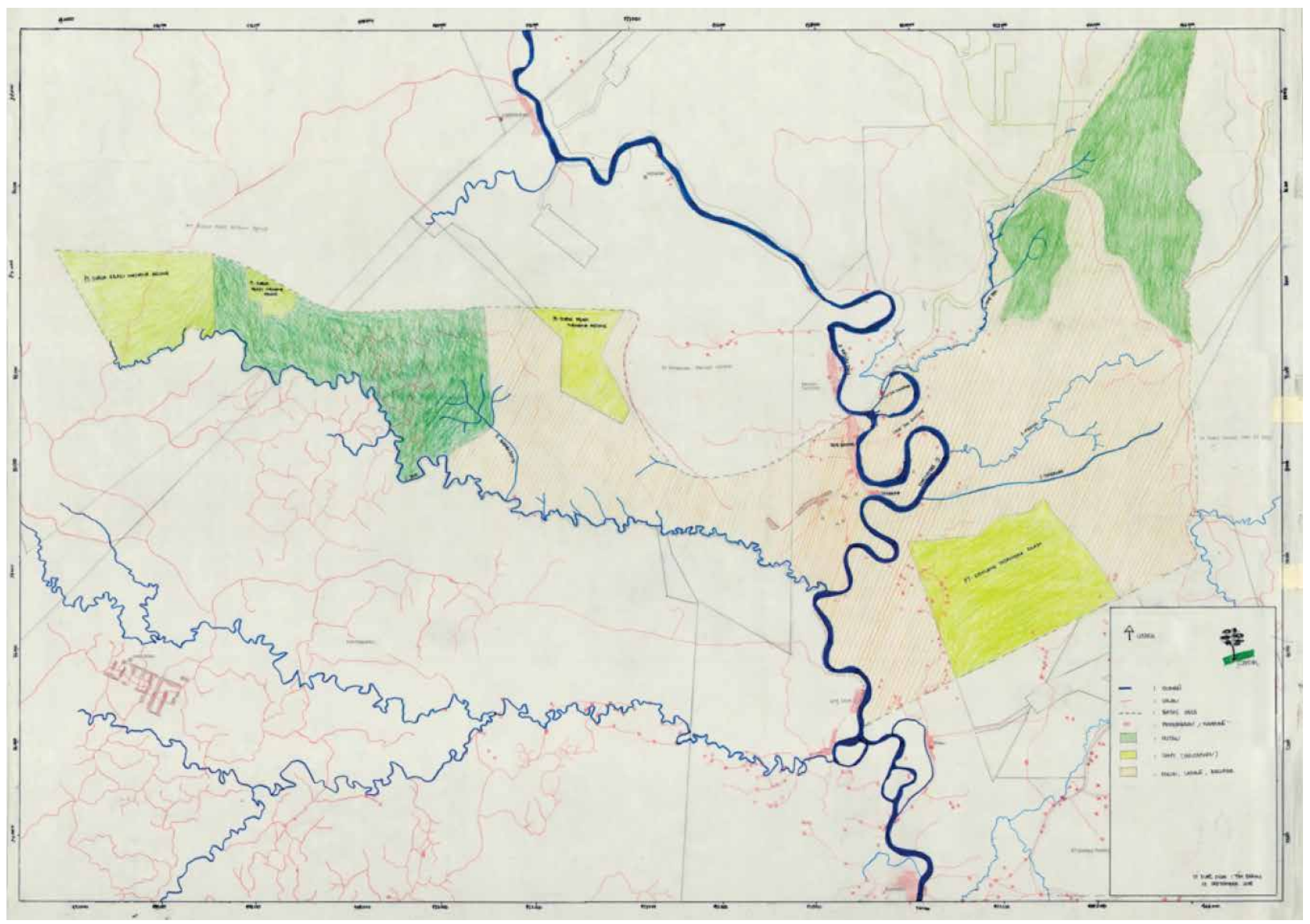

Gambar 6. Peta bersih.

Catatan: Peta ini berdasar dari peta yang disusun selama diskusi kelompok kecil, dengan menampilkan informasi mengenai kepemilikan lahan.

Kredit: Andini Desita Ekaputri 
yang ingin mengkoreksi sesuatu yang penting dalam peta. Akrabkan peserta dengan seluruh fitur peta, termasuk yang telah disusun (mis. jenis kepemilikan lahan) selama kegiatan pemetaan sebelumnya dengan informan kunci. Mintakan pembaruan atau koreksi jika diperlukan.

\subsection{Minta responden menjawab pertanyaan survei:}

Sebagaimana disebutkan sebelumnya, untuk GCS REDD+, pertanyaan selama pertemuan desa dan pertemuan perempuan terkait dengan perubahan tutupan lahan hutan dan kualitas hutan. Gunakan jenis-jenis kepemilikan lahan yang telah diidentifikasi pada saat diskusi kelompok kecil untuk menyusun pertanyaan penelitian. Tidak perlu membuat peta baru pada tahap ini, karena jika ada koreksi atau pembaruan sudah diminta sebelumnya, sejak awal pertemuan. Peta dari citra satelit dapat digunakan pada tahap ini untuk memeriksa informasi mengenai pembukaan hutan.

\subsection{Setelah diskusi kelompok:}

Enumerator akan menggunakan hasil pemetaan (tutupan hutan/perubahan kualitas) untuk memperkirakan luasan kawasan dalam tiap jenis kepemilikan lahan, dan mengisi jawaban terkait pertanyaan dalam Kuesioner desa dan Kuesioner perempuan. 


\section{Finalisasi peta setelah kerja lapangan}

Simpan salinan peta dasar pada kertas kalkir dari informan kunci dalam tabung plastik terlindung. Setelah kerja lapangan selesai, bawa peta ke tempat dimana peta bisa dipindai dan kirim pindaian ke ahli GIS yang akan mendigitalisasi dan mengintegrasikan peta sebagai salah satu layer yang berisi peta tiap lokasi. Langkah ini memungkinkan ahli GIS untuk menyusun luasan kawasan (dalam hektare) yang terkait dengan tiap jenis kepemilikan lahan, jarak ke pasar dan jalan terdekat (dalam $\mathrm{km}$ ), serta luasan kawasan (dalam hektare) dalam sengketa.

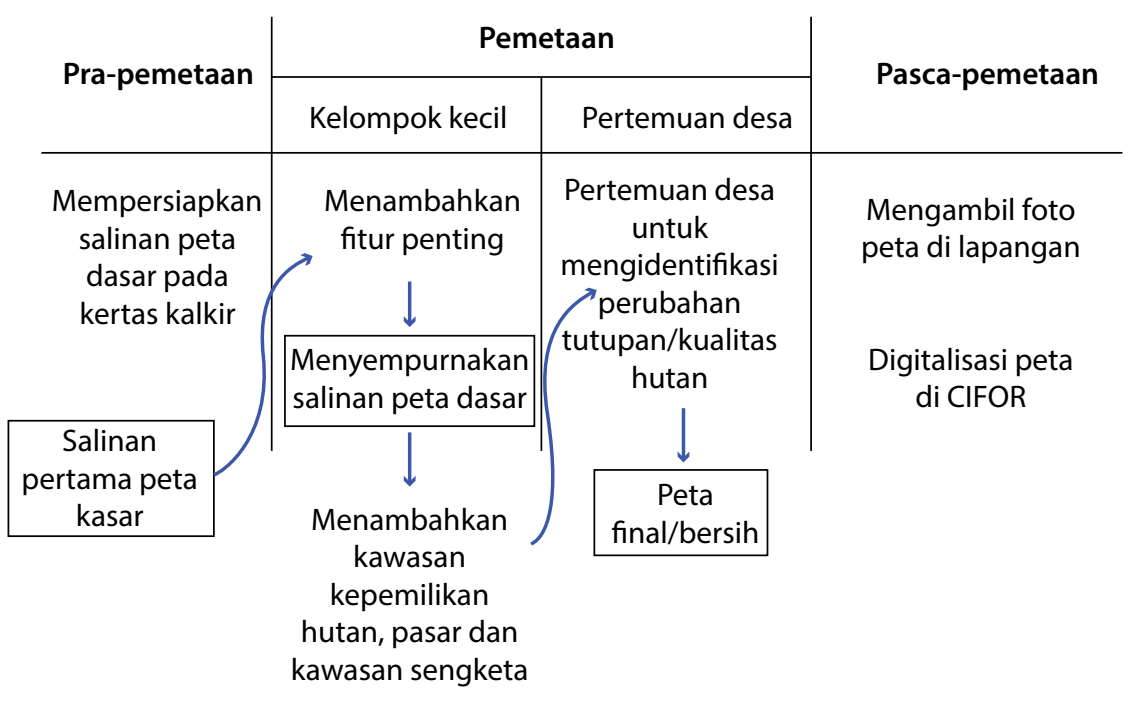

Gambar 7. Ringkasan langkah-langkah kegiatan pemetaan partisipatif di desa. 


\section{Referensi}

Anau N, Corbett J, Iwan R, van Heist M, Limberg G, Sudana M and Wollenberg E. 2003. Do communities need to be good mapmakers? Policy Brief. Jakarta, Indonesia: CIFOR.

Boissière M, Liswanti N, Padmanaba M dan Sheil D. 2007. People Priorities and Perceptions. Towards Conservation Partnership in Mamberamo. Bogor, Indonesia: Center for International Forestry Research (CIFOR).

Boissière M, Sassen M, Sheil D, van Heist M, de Jong W, Cunliffe R, Wan M, Padmanaba M, Liswanti N, Basuki I, et al. 2010. Researching local perspectives on biodiversity in tropical landscapes: lessons from ten case studies. In Lawrence A, ed. Taking Stock of Nature : Participatory Biodiversity Assessment for Policy, Planning and Practice. Cambridge, UK: Cambridge University Press. 113-41.

[CIFOR] Center for International Forestry Research. 2017. Global Comparative Study on REDD+. Bogor, Indonesia: CIFOR. Accessed 1 March 2019. www.cifor.org/gcs

Kingsolver A, Boissière M, Padmanaba M, Sadjunin E dan Balasundaram S. 2017. Cultural and participatory mapping. In Brunn SD and Dodge M, eds. Mapping Across Academia. Dordrecht: Springer Netherlands. https://doi.org/10.1007/978-94-024-1011-2
Padmanaba M, Boissière M, Sumantri $\mathrm{H}$ dan Achdiawan R. 2012. Perspectives on collaborative land use planning in Mamberamo Raya Regency, Papua, Indonesia: Case studies from Burmeso, Kwerba, Metaweja, Papasena, and Yoke. Laporan Proyek. Bogor, Indonesia: CIFOR.

Sheil D, Puri RK, Basuki I, van Heist M, Wan M, Liswanti N, Rukmiyati, Sardjono MA, Samsoedin I, Sidiyasa K et al. 2002. Exploring biological diversity, environment, and local people's perspectives in forest landscapes: Methods for a multidisciplinary landscape assessment. Bogor, Indonesia: Center for International Forestry Research.

Sunderlin W, Larson AM, Duchelle AE, Sills EO, Luttrell C, Jagger P, Pattanayak SK, Cronkleton P, Ekaputri AD, de Sassi C, et al. 2016. Technical guidelines for research on REDD+ subnational initiatives. Bogor, Indonesia: Center for International Forestry Research (CIFOR). https://doi. org/10.17528/cifor/006009

van Heist M. 2000. Participatory mapping of village territories. Bogor, Indonesia: Center for International Forestry Research (CIFOR). 

Dokumen ini ditujukan untuk para peneliti, pengawas penelitian lapangan dan enumerator yang memerlukan panduan dalam menyusun peta dengan partisipasi masyarakat lokal. Dokumen ini merupakan bagian dari Studi Komparatif Global mengenai REDD+ (GCS REDD+) yang dilakukan CIFOR dengan dukungan dana dari sejumlah donor.

Pemetaan partisipatoris merupakan sebuah cara untuk mendokumentasikan pemanfaatan dan kepemilikan lahan lintas kawasan. Pemetaan partisipatoris juga merupakan cara untuk mempelajari persepsi lokal mengenai bentang alam, dan perspektif lokal mengenai hutan dan manajemen lahan. Panduan teknis ini disusun berdasarkan pengalaman panjang CIFOR dalam menggunakan pemetaan partisipatoris dalam penelitian.

Dalam GCS REDD+, pelaksanaan pemetaan partisipatoris dilakukan di tingkat desa melalui diskusi kelompok terpimpin dalam mempelajari batas desa, kepemilikan lahan, kawasan sengketa, akses, dan pasar. Peta dasar dikembangkan dari citra satelit sebelum turun ke lapangan. Peta akhir didigitalisasikan agar kawasan yang dipilah berdasarkan kategori pemanfaatan lahan, tutupan lahan, dan kepemilikan lahan dapat diekstraksi untuk analisis lanjutan. Peta partisipatoris digunakan untuk membangun pemahaman bersama mengenai teritorial dengan penduduk desa dan pemangku kepentingan lokal lainnya. 